\title{
Development of a Frequency-Adjustable Tuned Mass Damper (FATMD) for Structural Vibration Control
}

\author{
Huaguo Gao, ${ }^{1}$ Congbao Wang, ${ }^{1}$ Chen Huang, ${ }^{2}$ Wenlong Shi, ${ }^{3}$ and Linsheng Huo $\mathbb{i D}^{2}$ \\ ${ }^{1}$ School of Civil Engineering, University of Science and Technology Liaoning, Anshan, Liaoning 114051, China \\ ${ }^{2}$ State Key Laboratory of Coastal and Offshore Engineering, Dalian University of Technology, Dalian, Liaoning 116024, China \\ ${ }^{3}$ Department of Civil Engineering, Shanghai University, Shanghai 200444, China
}

Correspondence should be addressed to Linsheng Huo; 1shuo@dlut.edu.cn

Received 2 February 2020; Revised 5 September 2020; Accepted 11 September 2020; Published 21 September 2020

Academic Editor: Vasant Matsagar

Copyright $\odot 2020$ Huaguo Gao et al. This is an open access article distributed under the Creative Commons Attribution License, which permits unrestricted use, distribution, and reproduction in any medium, provided the original work is properly cited.

\begin{abstract}
The tuned mass damper (TMD) can be applied to suppress earthquake, wind, and pedestrian- and machine-induced vibration in factory buildings or large span structures. However, the traditional TMD with a fixed frequency will not be able to perform effectively against the frequency variations in multiple hazards. This paper proposed a frequency-adjustable tuned mass damper (FATMD) to solve this limitation of current TMD. The FATMD presented in this paper is composed of a simple assembly consisting of a supported beam with a mass, in which the frequency of the FATMD is changed by adjusting the span of the beam. The kinematic equation of a single degree of freedom (SDOF) structure installed with an FATMD is established to analyze the effect of the damping ratio, mass ratio, and stiffness on the vibration damping. The fundamental frequency of the FATMD at different spans is verified by simulation and experiments. Forced vibration experiments with different excitation frequencies are also conducted to verify the performance of the FATMD. The results show that the proposed FATMD can effectively suppress the vertical vibration of structures at different excitation frequencies, including frequencies at a range higher than what a traditional TMD may not be able to suppress. Additionally, the proposed FATMD is applied to a long-span pedestrian bridge which vibrates frequently due to the walking of pedestrians, the running of escalators, and earthquakes. The numerical results indicate that the FATMD can effectively reduce the vertical vibration of the pedestrian bridge under the excitations of pedestrians, escalators, and earthquakes.
\end{abstract}

\section{Introduction}

The rapid development of mechanical automation has given rise to the increasing presence of large equipment in factories and the construction of large span structures. Factory buildings and large span structures often house high-power equipment, which can generate strong vibrations that can affect the integrity of the surrounding structures. If the structural vibration exceeds a certain level, it will negatively affect the function and performance of other devices in the building $[1,2]$. The vibration can also lead to a reduced level of comfort for the working personnel $[3,4]$. In extreme cases, the vibration can even cause structural damage [5]. There are numerous ways to reduce the vibration of a structure within comfortable levels. One way is to increase the stiffness of the structure, thereby increasing the natural frequency of the structure and shifting it from the range in which it can be easily reached [6,7]. Wang et al. [8] strengthened the floor slab and secondary beams to increase the natural frequency of the floor, thereby reducing floor vibrations caused by wheat bran finishers and flour purifiers. However, increasing stiffness may waste the performance of the material and can become expensive. Another method is to utilize vibration-control technologies. Since the concept of vibration control was first proposed by Yao [9] in 1972, numerous vibration-control techniques have been developed and applied to enhance the functionality and safety of structures. Lee et al. [10] utilized multiple viscoelastic dampers to suppress microvibrations in the floor induced by automated guided vehicles in thin-film transistor liquid crystal display factories. The dampers effectively suppressed the dynamic responses to a desired vibration criterion level. 
Zordan et al. [11] proposed an active micromachined vibration isolator to isolate high-frequency mechanical vibrations in low-pressure environments, which is suitable for use in or as packaging for sensitive electronic and microelectromechanical systems (MEMS). Setareh et al. [12] proposed a pendulum tuned mass damper to control the excessive vibrations of building floors.

As one of the most popular and flexible vibration control devices, the tuned mass damper (TMD) boasts the advantages of a simple set up, effective vibration suppression, and not needing an energy source (i.e., passive control). TMDs are widely applied in the engineering community, such as in the Condo tower in San Francisco and the Citicorp Building in New York City. Sun et al. [13] analyzed the vibration control effect of TMDs installed on the Chongqing Bridge under Typhoon Chan-hom and demonstrated the effectiveness of the TMDs and their ability to suppress vibrations under a wide range of wind conditions. Caetano et al. $[14,15]$ evaluated the efficiency of the lateral and vertical TMDs on the Pedro e Inês footbridge in Portugal. Carpineto et al. [16] simulated the dynamic response of suspension footbridges with and without multiple TMDs (MTMDs) under pedestrian-induced excitations. The simulation indicated that MTMDs can effectively reduce vibrations of suspension footbridges. Considering uncertainties present in the structural parameters and the MTMD design, Vellar et al. [17] proposed a new methodology for simultaneous optimization of parameters and positions of MTMDs in buildings that may be subjected to earthquakes. They applied the proposed methodology in a 10-story building to confirm its effectiveness. Elias et al. [18] applied different TMD schemes to reduce structural dynamics under wind and earthquake excitations and found that, for the purposes of multihazard response control, distributed TMDs with equal stiffnesses are preferable compared to those with equal masses. Gerges and Vickery [19] demonstrated the superiority a wire rope spring TMD over a normal TMD and verified the vibration control performance of the new TMD through shaking table tests. He et al. [20] set up TMDs in a cabin to restrain large vibration displacements caused by loads from offshore floating wind turbines, which often face harsh marine conditions. The researchers also simulated the dynamic responses of the wind turbine with and without TMDs under different combined wind and wave loads. Their analyses showed that TMDs can effectively reduce vibration responses for offshore floating wind turbines. Wu et al. [21] proposed a magnetic TMD which is reliable and robust in controlling the vibrations of structures. Bakre and Jangid [22] derived optimum parameters for a TMD system attached to a viscous damped main system. The TMD was able to be tuned for various combinations of excitation and response parameters. Kang and Peng [23] determined the optimal parameters for large mass ratio TMDs subjected to harmonic loads and random, stationary white noise loads and studied the control effect of large mass ratio TMDs. Lu et al. [24] proposed a particle TMD and evaluated its damping performance through aeroelastic wind tunnel tests on a benchmark high-rise building. The results showed that the particle TMD can effectively suppress the wind-induced vibration of the structure. Lu et al. [25] evaluated the effectiveness of the eddy-current TMD (EC-TMD) in suppressing the vibration of the structure through shaking table tests, and the results showed that the EC-TMD can effectively reduce the displacement response, acceleration response, interstory drift ratio, and maximum strain of the columns under different earthquake excitations. Zhang et al. [26] proposed a pounding TMD (PTMD) and numerically simulated the PTMD on a $55 \mathrm{~m}$ tower model to verify the effectiveness of the pounding TMD. The results demonstrated that the PTMD is able to suppress vibrations faster and more strongly than the normal TMD. Xue et al. [27] examined the application of the PTMD in reducing the vibration of offshore jacket-type platforms and showed that the PTMD performed better than the traditional TMD in the desired frequency bandwidth. He et al. [28] proposed a TMD with poles and torsional pendulums (TMDPP). The TMDPP can simultaneously control the translational responses and the torsional angle of asymmetric structures. Santos et al. [29] tested a TMD control system to reduce the excessive vibrations of a gym floor in a commercial building in Brasilia, Brazil. Nguyen [30] optimized the parameters of a symmetric TMD using an analytical method that considers specific vibration duration and stability criteria. Tarng et al. [31] mounted a piezoelectric inertia actuator on the cutting tool, which can suppress the vibration and improve cutting stability in turning operations. Yang et al. [32] designed and optimized MTMDs to increase the chatter resistance of machine tool structures.

However, a major drawback of the conventional TMD is that if the TMD is detuned form the natural frequency, a significant loss of vibration control performance can occur. Therefore, the conventional TMD with a fixed frequency cannot perform effectively against the frequency variations in multiple hazards. To overcome this issue, many semiactive or active methods have been proposed. Chang et al. [33] reported the use of an adjustable, vertically moving TMD (VTMD) to suppress machine-induced vertical vibration of structures. Abdel-Rohman et al. [34] studied the influence of the time delay on the performance of a semiactive TMD and proposed two methods to compensate for the time delay and ensure the vibration suppression effect. Jiang and Hanagan [35] proposed a semiactive variable damping TMD (SAVDTMD) with piezoelectric friction dampers as an alternative to existing methods to control floor vibrations, especially vibrations induced by pedestrian traffic. Esteki et al. [36] described the use of a magnetorheological fluidbased semiactive TMD to suppress the seismic response of a 40-story steel-frame building in Vancouver. The new semiactive suppressed structural vibrations more effectively than the classic passive TMD. Nagarajaiah et al. [37, 38] developed a semiactive or smart TMD (STMD) using a semiactive variable stiffness system, which is robust against changes in the natural frequency of the host structure since the STMD always stays tuned. Ryan et al. [39] proposed an adaptive passive vibration absorber and experimentally validated the effectiveness through experiments. The results demonstrated that the adaptive absorber is able to achieve $25 \mathrm{~dB}$ of attenuation in the vibration of a model building. Contreras 
et al. [40, 41] proposed an adaptive length pendulum smart TMD (ALP-STMD) in which natural frequencies are time invariant. They experimentally validated the ability of an ALP-STMD to adequately control a structural system. Similar devices were applied towards bridge vibration control [42]. Shi et al. [43] proposed a self-adjustable variable mass TMD (SAVM-TMD) and experimentally validated the effectiveness under different pedestrian excitations. The results demonstrated that the SAVM-TMD is able to suppress pedestrian vibrations better than the normal TMD. Venanzi et al. [44] proposed an active TMD to mitigate wind-induced vibrations of tall buildings and optimized the number and positions of active TMDs. Rahman et al. [45] investigated the seismic performance of a 10-story building and demonstrated the efficiency of using multiple adaptive TMD to dampen seismic-induced structural vibrations.

The traditional TMD is a type of frequency sensitive control device. Thus, the potential for unintended detuning of the TMD's natural frequency is a major drawback of the traditional TMD. When the frequency of the TMD is not matched with the frequency of the host structure, the TMD can suffer a significant loss of vibration control performance. The vibration frequencies of structures are often varied due to the degradation of structural parameters in multiple hazard scenarios, which requires that the frequency of TMD should be easily tuned to better respond to this variation. The natural frequency of the TMD is determined partially by its stiffness, which, in current TMDs, is usually provided by springs. The stiffness of the spring is difficult to be set precisely due to unavoidable errors in the manufacturing process, and thus, it is difficult to guarantee the exact frequency of the vibration control system. Therefore, the TMD is usually adjusted by changing the mass of the system after the spring is fabricated. However, doing so means that there is a very narrow tuning range for setting the frequency of the TMD. Furthermore, the traditional TMD is only suitable for mitigating low-frequency vibrations and has trouble of controlling high frequency vibrations often generated by mechanical equipment. To overcome these issues, a frequency-adjustable tuned mass damper (FATMD) is proposed in this study. The FATMD utilizes a beam instead of a spring to provide the stiffness to the control device and can effectively suppress high-frequency vibrations. The frequency of the FATMD can be adjusted by adjusting the span of the beam. In this paper, the kinematic equations of the structure with a FATMD are established to analyze the effect of damping ratio, mass ratio, and stiffness on its ability to dampen vibrations. Subsequently, the fundamental frequencies of the FATMD with different adjusted spans are verified by simulation and experiments. To verify the vibration suppression performance of the FATMD, the FATMD is subjected to forced vibrations at different excitation frequencies.

\section{The FATMD}

The schematic of the FATMD is shown in Figure 1. The FATMD consists of an easy-to-implement assembly of a bottom plate, vertical columns, a weighted steel plate, and a beam. As shown in Figure 1(b), the pedestals of columns (3) are bolted between the bottom plate (1) and the pressure plate (2). Before the columns are fixed, the span of the beam (6) can be adjusted by moving the pedestals of the columns (3) along the length of the bottom plate (1) and, thereby, allow the continuous adjustment of the natural frequency of the FATMD. The beam (6) is installed on the rectangular platform of formed by the columns (3) and is fixed via the bolted column fastener (7). The weighted box (4) is fixed to the beam (6) through a set of fasteners. The beam (6) is clamped between the weighted box (4) and the fastener, and a gasket placed between the beam and the weighted box prevents the weighted box from sliding along the beam's axis. The bolt holes are set to straight notches, which are perpendicular to the axial direction. The weighted box (4) can be finely adjusted along the length of the beam to avoid any eccentricity of the FATMD caused by the weight box. The counterweight steel plate (5) hangs from the weighted box and, thus, reduces the footprint of the FATMD. The frequency of the FATMD can be finely adjusted by changing the mass of the plates.

\section{Control Equations of an SDOF Structure with the FATMD}

The TMD is one of the earliest passive control devices used in structural vibration control. When the main structure vibrates under external excitation, the TMD control system is driven to vibrate together with the structure. Then, inertial forces generated by the relative motion of the TMD acts against the motions of the structure and, thus, can reduce the dynamic response of the structure. To illustrate the working principle, a single degree of freedom (SODF) primary structure installed with the FATMD is illustrated in Figure 2, where $m_{1}, c_{1}$, and $k_{1}$ are, respectively, the mass, damping, and stiffness of the SDOF structure. $m_{2}, c_{2}$, and $k_{2}$ are the mass, damping, and stiffness of the FATMD, respectively.

According to D'Alembert's principle, the kinematic equations of the SDOF structure with the FATMD are as follows:

$$
\begin{aligned}
& m_{1} \ddot{x}_{1}+\left(c_{1}+c_{2}\right) \dot{x}_{1}-c_{2} \dot{x}_{2}+\left(k_{1}+k_{2}\right) x_{1}-k_{2} x_{2}=f(t), \\
& m_{2} \ddot{x}_{2}+c_{2}\left(\dot{x}_{2}-\dot{x}_{1}\right)+k_{2}\left(x_{2}-x_{1}\right)=0,
\end{aligned}
$$

where $x_{1}, \dot{x}_{1}$, and $\ddot{x}_{1}$ are the displacement, velocity, and acceleration of the structure relative to the ground, respectively. $x_{2}, \dot{x}_{2}$, and $\ddot{x}_{2}$ are the displacement, velocity, and acceleration of the FATMD relative to the ground, respectively.

The equations can be solved by expressing them in the form of a transfer function. Thus, after applying the Laplace transform,

$$
\begin{aligned}
& {\left[m_{1} s^{2}+\left(c_{1}+c_{2}\right) s+\left(k_{1}+k_{2}\right)\right] X_{1}-\left(c_{2} s+k_{2}\right) X_{2}=f(s),} \\
& \left(m_{2} s^{2}+c_{2} s+k_{2}\right) X_{2}-\left(c_{2} s+k_{2}\right) X_{1}=0
\end{aligned}
$$

where $s$ represents the independent variable after the Laplace transform of the original function. 


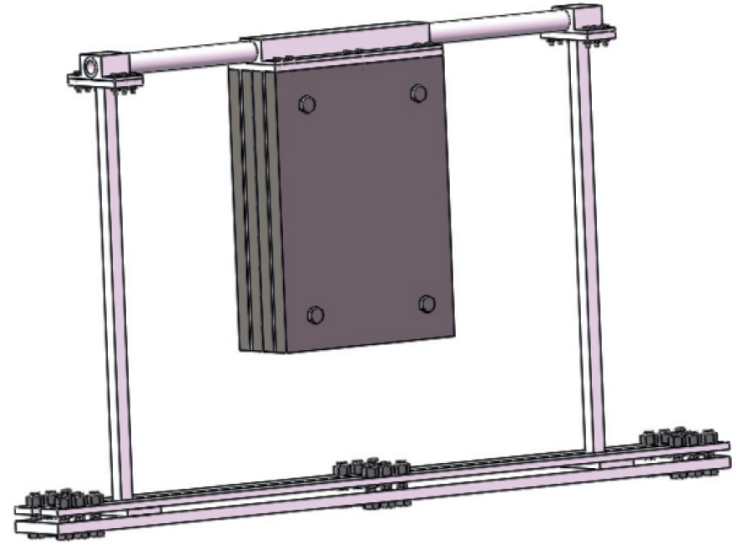

(a)

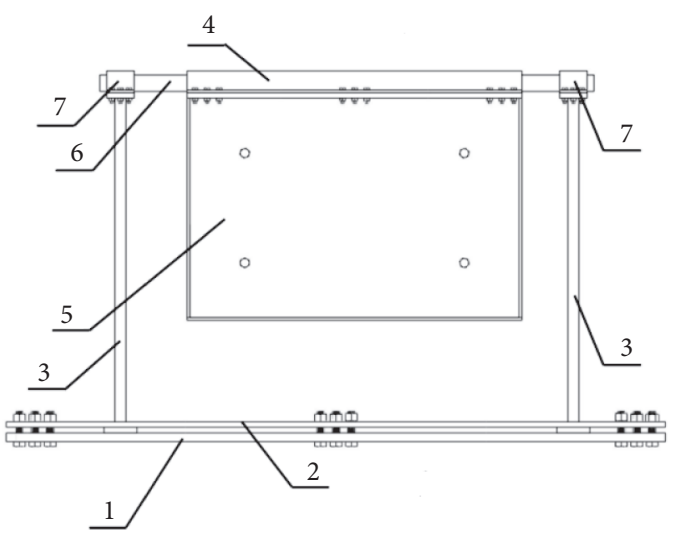

(b)

Figure 1: Schematic of the FATMD. (a) Three-dimensional schematic, (b) elevation drawing. 1-bottom plate; 2-pressure plate; 3-column; 4-weighted box; 5-counterweight steel plate; 6-Beam; and 7-column fastener.

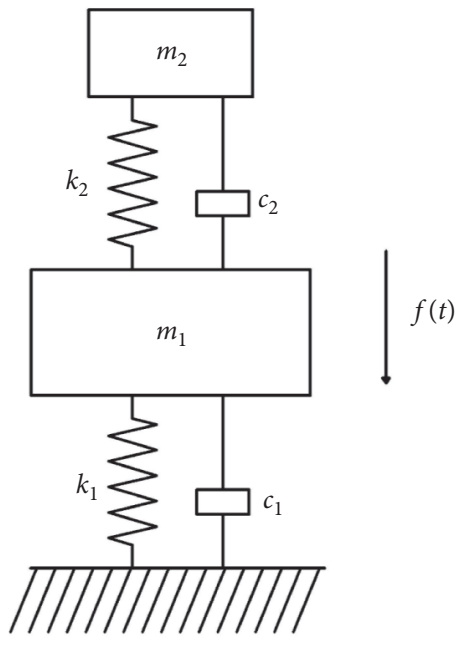

Figure 2: Diagram of an SDOF structure with an installed FATMD.

Equation (5) can be organized as follows:

$$
\left(s^{2}+2 \omega_{1} \xi s+\omega_{1}^{2}\right) X_{1}+\mu s^{2} X_{2}=\frac{f(s) \lambda^{2} \mu \omega_{1}^{2}}{k_{2}},
$$

where $\omega_{1}$ and $\xi_{1}$ are, respectively, the frequency and the damping ratio of the structure. $\mu$ is the ratio of the mass of the TMD to the total mass of the structure.

$$
\begin{aligned}
\omega_{1} & =\sqrt{\frac{k_{1}}{m_{1}}}, \\
\xi_{1} & =\frac{c_{1}}{2 m_{1} \omega_{1}}, \\
\mu & =\frac{m_{2}}{m_{1}} .
\end{aligned}
$$

Thus, the overall transfer function for the primary structure is as follows:

$$
H(s)=\frac{1}{m_{1} s^{2}+\left(c_{1}+c_{2}\right) s+\left(k_{1}+k_{2}\right)-\left(\left(\left(c_{2} s+k_{2}\right)^{2}\right) /\left(m_{2} s^{2}+c_{2} s+k_{2}\right)\right)} .
$$

\section{Parametric Analysis of the FATMD}

The previous section considered the SDOF structure coupled with an FATMD (Figure 2) as an analytical model and established the control equations for the whole system. In this section, a parametric analysis for the system under the sinusoidal excitation is provided to verify the influences of parameters of the FATMD on its effectiveness, which can provide useful information for designing the FATMD. The parameters of the FATMD are as follows based on practicality:

(1) $\lambda$ : the ratio of the frequency of the FATMD to the fundamental frequency of the structure

(2) $\mu$ : the ratio of the mass of the FATMD to the total mass of the structure

(3) $\xi$ : the damping ratio of the FATMD

As shown in Figure 3, the logarithmic amplitude-frequency characteristic curves of the structure with and without the FATMD are plotted for different values of $\lambda$ when $\mu=0.01$. The curves can illustrate the trend of changes on the amplitude of the structural response at different frequencies. By comparing the amplitudes of the uncontrolled and controlled structural vibrations, it is noted that the vibration of the structure can be effectively reduced by the FATMD. When the frequency of the external excitation is $15.7 \mathrm{~Hz}$, the vibration of the structure without control peaks is due to resonance. The vibration suppression effect of the FATMD is stable between $\lambda=0.9-1.1$, with $\lambda=1.0$ being a relatively optimal value according to the curves. Additionally, the vibration suppression effect of the FATMD is pronounced when the frequency of the FATMD matches the excitation frequency. 


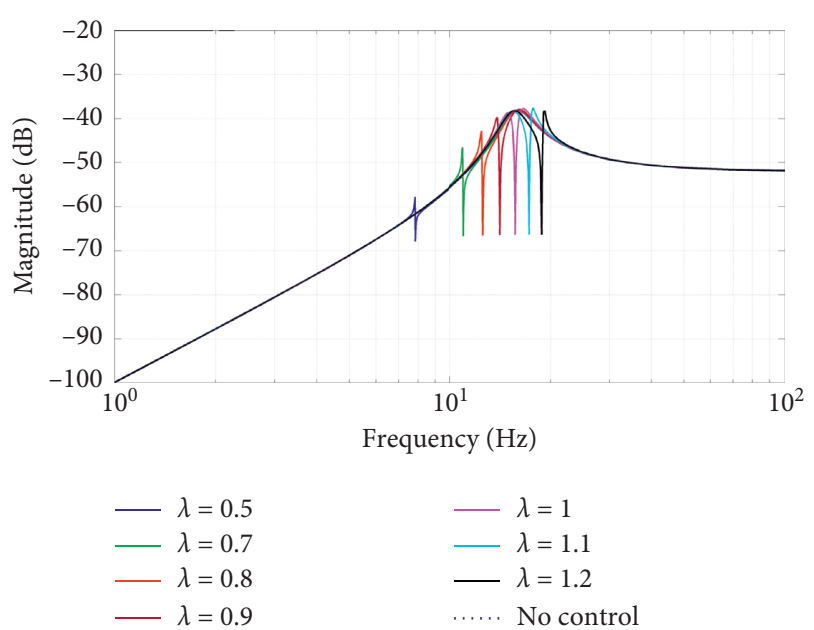

FIgURE 3: Logarithmic amplitude-frequency characteristic curves of the structure with and without the FATMD (varying $\lambda$ ).

In Figure 4, the logarithmic amplitude-frequency characteristic curves of the system are plotted for different values of $\mu$ when $\lambda=1.0$. A comparison of the seven curves with and without control reveals the obvious vibration mitigation effect of the FATMD. By increasing the mass of the FATMD, the effective bandwidth of the FATMD widens and the vibration suppression effect on the structural vibrations also increases. Furthermore, in Figure 5, the logarithmic amplitude-frequency characteristic curves of the system are plotted for different values of $\xi$ when $\lambda=1.0$ and $\mu=0.01$. The figure shows that the greater the damping ratio, the weaker the vibration reduction effect of the FATMD becomes. Thus, the damping ratio of the FATMD should be minimized in the cases that the frequencies of excitation deviate far from the one of the structure.

\section{Vibration Control Experiments of the FATMD}

5.1. Experimental Setup. To verify the vibration suppression performance of the FATMD, the FATMD and the structure are subjected to forced vibrations at different excitation frequencies. The primary structure is a model steel floor elevated on four steel legs. The size of the steel floor is $100 \times 20 \times 1.5 \mathrm{~cm}$. The height of the structure is $40 \mathrm{~cm}$, and the total weight of the structure is $32.52 \mathrm{~kg}$. The natural frequency of the structure is $25.8 \mathrm{~Hz}$. As shown in Figure 6, the FATMD mainly consists of a bottom plate, vertical columns, a steel weight, and a beam, similar to the schematic shown in Figure 1. The beam is a steel pipe with a length of $1 \mathrm{~m}$ and $1 \mathrm{~mm}$ thick steel walls. Two kinds of steel pipes with different diameters are tested for the verification experiment. One pipe has a line inner radius of $5 \mathrm{~mm}$, and the other has a line inner radius of $6 \mathrm{~mm}$. The rubber gaskets are installed between the column and the beam to prevent the beam from sliding in the axial direction between the platform and fastener of the column. A mass of $0.5 \mathrm{~kg}$ is fixed in the middle of the beam and the frequency of FATMD can be fine-tuned by changing the mass.
As shown in Figure 7, the shaker is installed at the bottom of the primary structure and is used to excite the vertical vibration of the primary structure during the test. The shaker (model: JZK-20) can be controlled by a signal generator and can continuously output a sinusoidal signal with a frequency between $1-10000 \mathrm{~Hz}$. Without any loads, the maximum displacement is $10 \mathrm{~mm}$, and the maximum output force is $200 \mathrm{~N}$. Two accelerometers (model: Lance LC0101) are mounted to measure the absolute acceleration. One is fixed onto the primary structure, and the other is fixed onto the FATMD. Data are collected by using an acquisition device (Model: NI 6366) connected to a laptop installed with LabVIEW.

To demonstrate that the frequency of the FATMD is adjustable, the first-order frequency of the FATMD under different spans is measured by the knocking method [46]. Then, the FATMD is tested with forced vibrations at different excitation frequencies and configurations. The direction of the applied excitation is vertical. The vibrations of the structure and the FATMD are also vertical.

5.2. Experimental Results. The first-order frequency of the FATMD at different adjusted spans is plotted in Figures 8 and 9 , and the values of the frequency are listed in Table 1. $L$ is length of the beam span in the FATMD. The figures show that the frequency of the FATMD decreases when the beam span increases. As shown in Table 1, when the beam has a radius $(r)$ of $5 \mathrm{~mm}$ and a span of $0.5 \mathrm{~m}$, the first-order frequency of FATMD is $38 \mathrm{~Hz}$. When the span of the beam increases to $1 \mathrm{~m}$, the first-order frequency of FATMD is $17.3 \mathrm{~Hz}$. As shown in Table 1, when the beam has a radius of $6 \mathrm{~mm}$ and a span of $0.5 \mathrm{~m}$, the first-order frequency of FATMD is $42.7 \mathrm{~Hz}$. When the span of the beam increases to $1 \mathrm{~m}$, the first-order frequency of FATMD is $20.1 \mathrm{~Hz}$. The data, therefore, demonstrates that by changing of the beam span, the frequency of the FATMD can be adjusted.

To evaluate the vibration control performance of the FATMD, the vibration reduction ratio $(J)$ is defined as described in equation (8).

$$
J=\frac{a_{0}-a_{1}}{a_{0}} \times 100 \%,
$$

where $a_{1}$ and $a_{0}$ are the maximum vertical acceleration of the structure with and without the FATMD, respectively.

As shown in Figure 10, the vertical accelerations of the primary structure with and without the FATMD are plotted against time for the tested excitation frequencies. Table 2 lists the vibration reduction ratios of the FATMD under different excitation frequencies. In the experiment, the span was adjusted to make the frequency of the FATMD match the excitation frequency. When frequencies of the excitation and FATMD are both $26.5 \mathrm{~Hz}$, the vibration reduction ratio of the FATMD is $96.1 \%$, thus effectively suppressing the forced vibration of the structure. As shown in Figures $10(\mathrm{~g})-10(\mathrm{n})$, the FATMD can still effectively suppress the structural vibration at other high frequency excitations. For example, when the excitation frequency increases to $38.0 \mathrm{~Hz}$, the vibration reduction ratio is $64.7 \%$. In case where the 


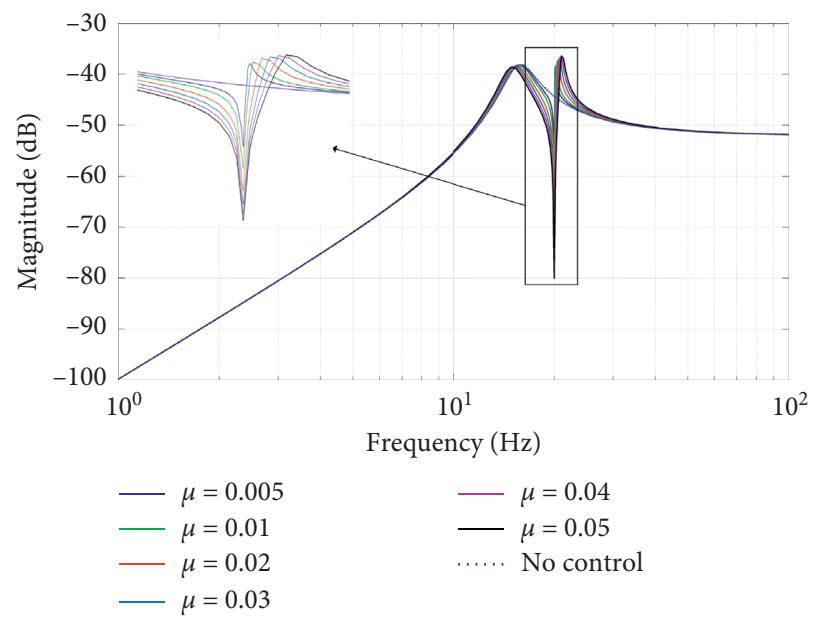

FIGURE 4: Logarithmic amplitude-frequency characteristic curves of the structure with and without the FATMD (varying $\mu$ ).

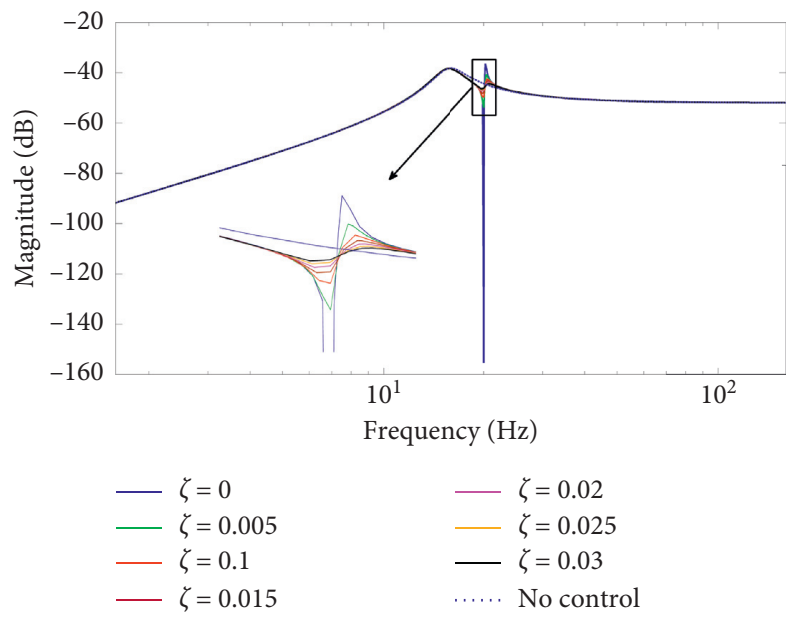

FIGURE 5: Logarithmic amplitude-frequency characteristic curves of the structure with and without the FATMD (varying $\xi$ ).

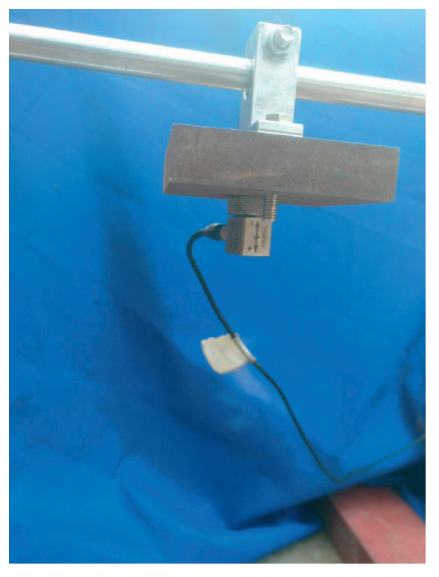

(a)

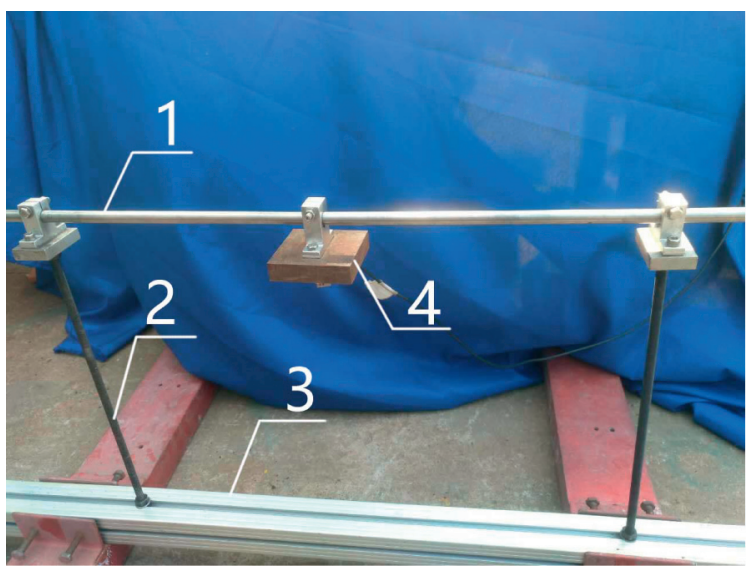

(b)

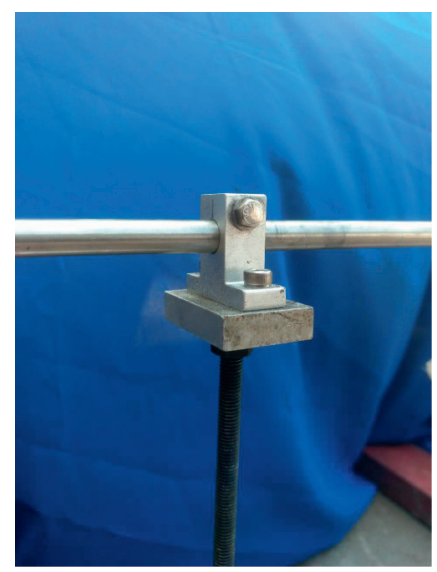

(c)

Figure 6: Photos of the FATMD (1-beam; 2-column; 3-bottom plate; and 4-counterweight). 


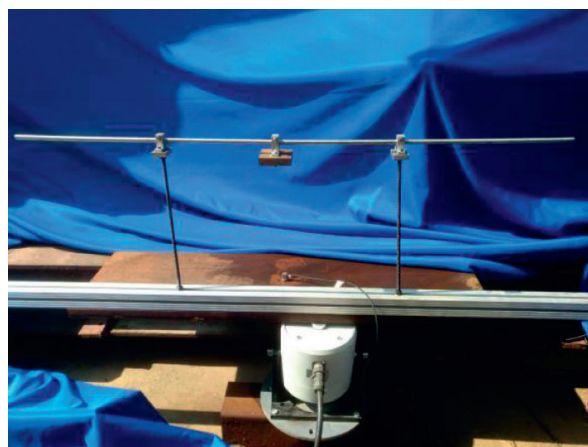

(a)

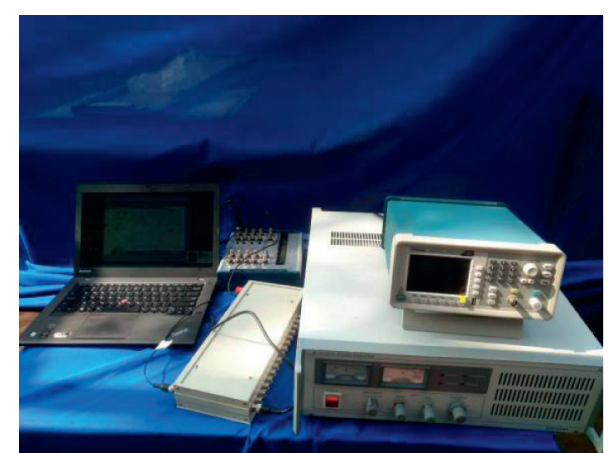

(b)

FIgURE 7: The experimental setup and data acquisition system.

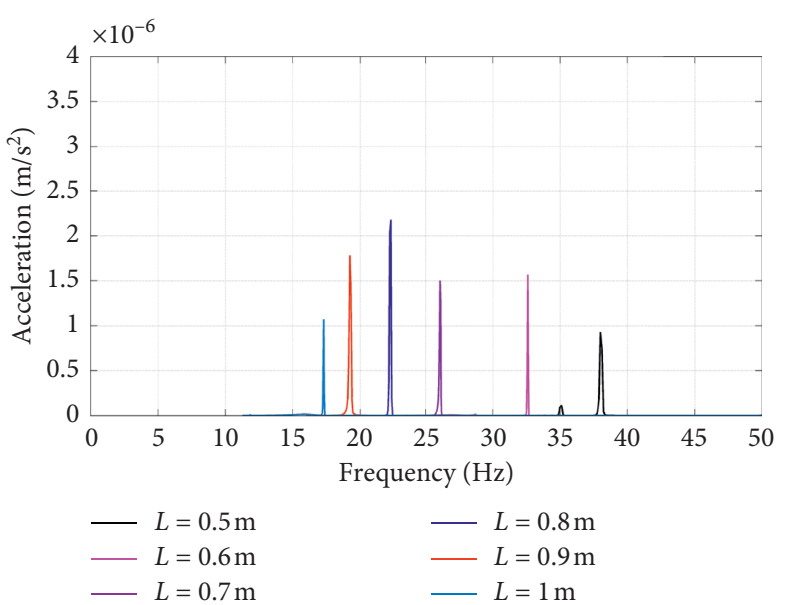

Figure 8: The first-order frequency of the FATMD with different spans $(r=5 \mathrm{~mm})$.

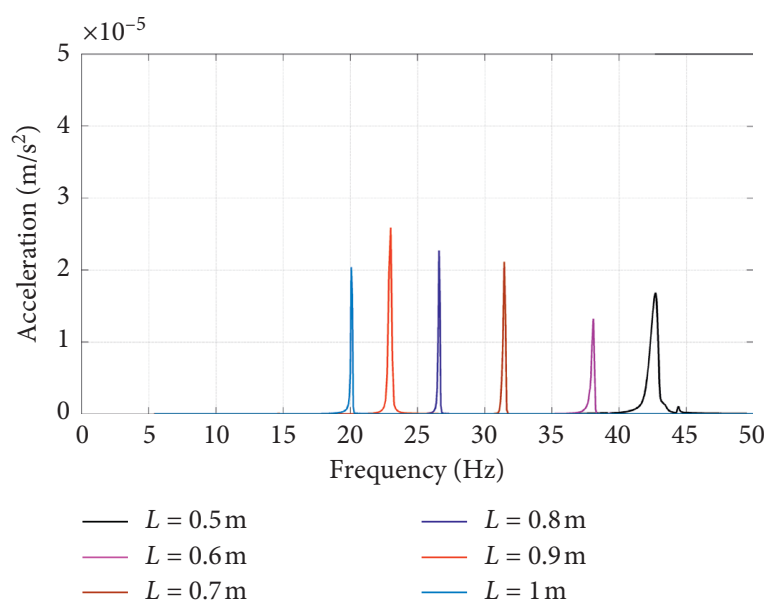

FIgURe 9: The first-order frequency of the FATMD with different spans $(r=6 \mathrm{~mm})$.

TABle 1: First-order frequency of the FATMD at different spans.

\begin{tabular}{cccccccc}
\hline \multicolumn{2}{c}{ Span $(\mathrm{m})$} & 0.5 & 0.6 & 0.7 & 0.8 & 0.9 & 1.0 \\
\hline \multirow{2}{*}{ Frequency $(\mathrm{Hz})$} & $r=5 \mathrm{~mm}$ & 38.0 & 32.6 & 26.1 & 22.3 & 19.2 & 17.3 \\
& $r=6 \mathrm{~mm}$ & 42.7 & 38.0 & 31.5 & 26.5 & 23.0 & 20.1 \\
\hline
\end{tabular}

frequency of the external excitation or structure changes, the beam span can be changed to adjust the frequency of the FATMD accordingly to preserve highly effective vibration suppression.

\section{Vibration Control of a Long-Span Pedestrian Bridge with the FATMD}

There is a pedestrian bridge in Shenyang, China, with the span of $49 \mathrm{~m}$. The main structure of the bridge is a singlespan steel box girder with the simple support at both ends. The deck width of the bridge is $3 \mathrm{~m}$, and the linear density of the bridge is $1.179136 \mathrm{~kg} / \mathrm{m}$. The moment of inertia of the girder section is $0.0694 \mathrm{~m}^{4}$, and the elastic modulus is $200 \mathrm{GPa}$. The first frequency of the structure on the vertical direction is $2.2 \mathrm{~Hz}$, which is close to the one of pedestrian walking. As a result, the large vibration can be felt when people walk through the bridge. In addition, the running of escalators connected to the bridge can also excite the vibration of the bridge. The vibration of bridge due to the walking of pedestrians and running of escalators can cause the uncomfortableness of people on the bridge and even result the fatigue damage of the structure. An FATMD is installed on the midspan of the pedestrian bridge to reduce the vertical vibrations under the excitations of pedestrians, escalators, and earthquakes. As shown in Figure 11, the FATMD can be installed under the guardrails of the pedestrian bridge, which will not affect the normal use of the bridge. The ratio of the total mass of the FATMD to the one of the bridge is $2 \%$. Considering that the counterweight steel plates of the FATMD are relatively large, the stiffness and the span of the beam on the FATMD should be designed reasonably.

Figure 12 shows the simplified analysis model of the pedestrian bridge installed with an FATMD. The kinematic equations of the bridge with the FATMD are as follows:

$$
\begin{aligned}
& \mathrm{EI} \frac{\partial^{4} y}{\partial x^{4}}+\bar{M} \frac{\partial^{2} y}{\partial t^{2}}+C \frac{\partial y}{\partial t}=F+f, \\
& m \ddot{y}_{1}+c\left(\dot{y}_{1}-\dot{y}_{0}\right)+k\left(y_{1}-y_{0}\right)=0,
\end{aligned}
$$

where EI is the flexural stiffness of the bridge. $M(-)$ is the linear density of the bridge. $m, c$, and $k$ are the mass, 


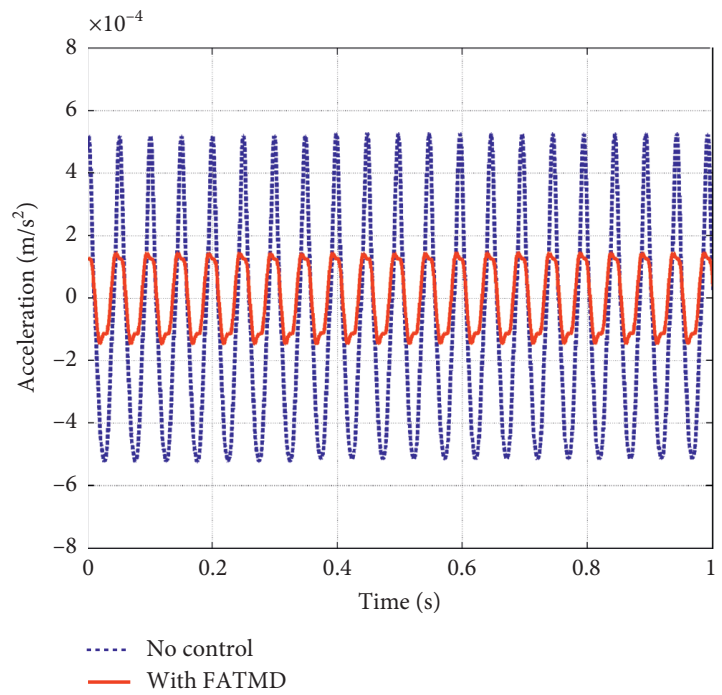

(a)

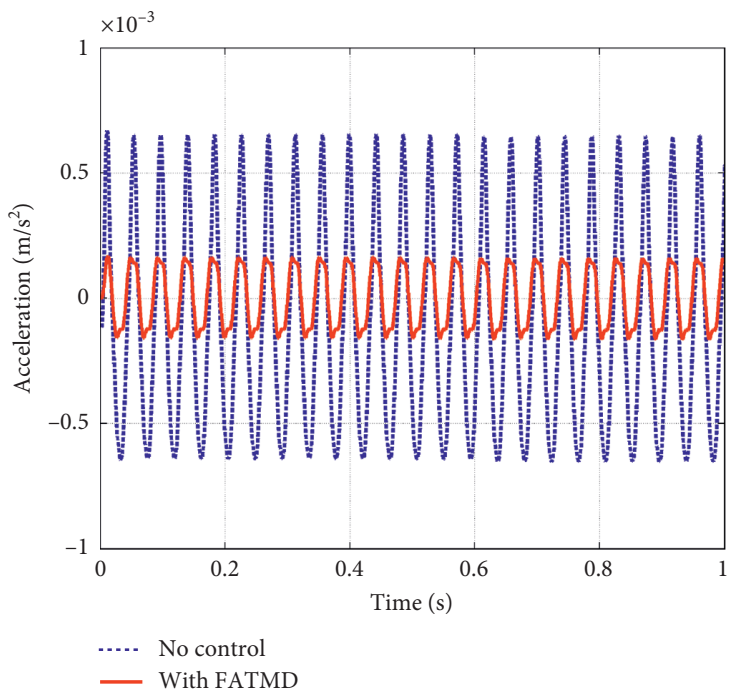

(c)

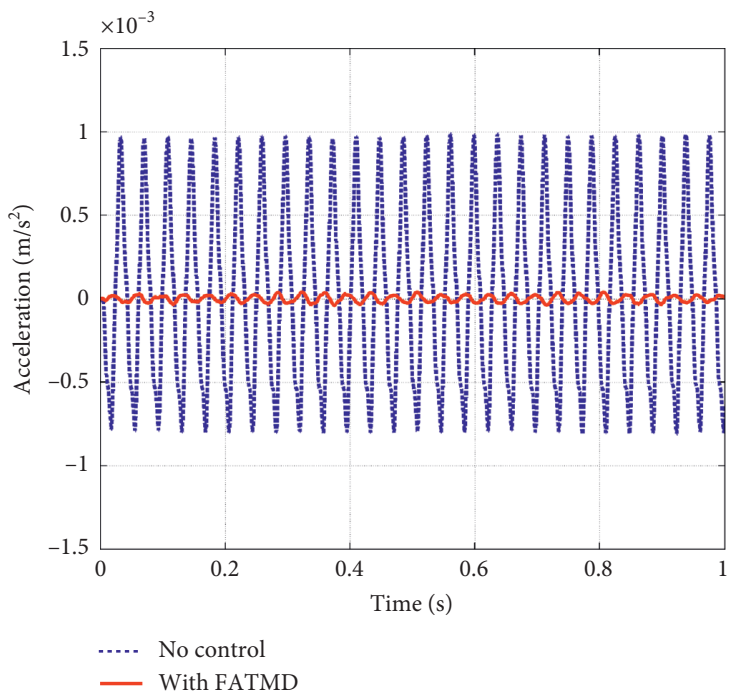

(e)

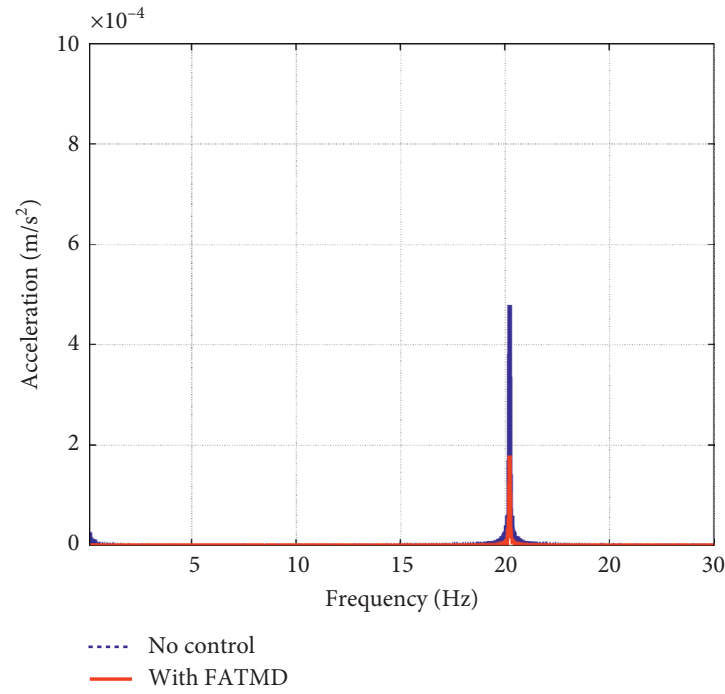

(b)

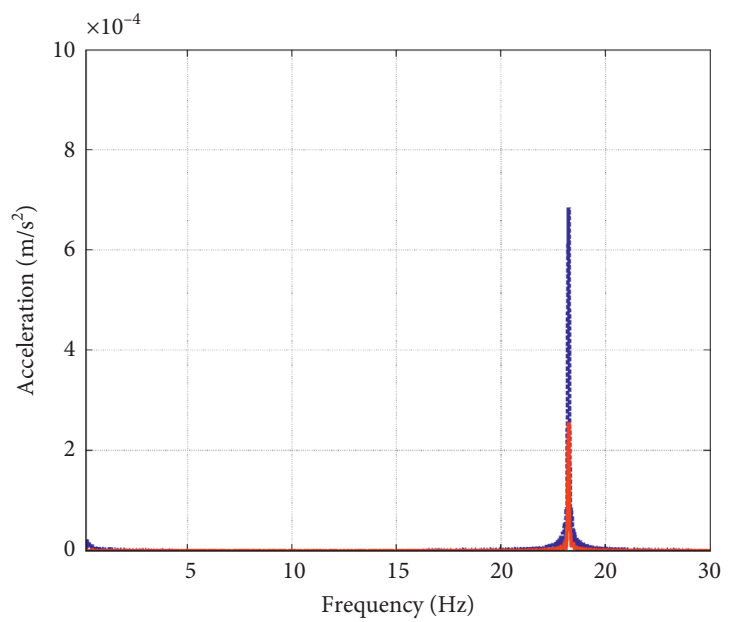

..... No control

— With FATMD

(d)

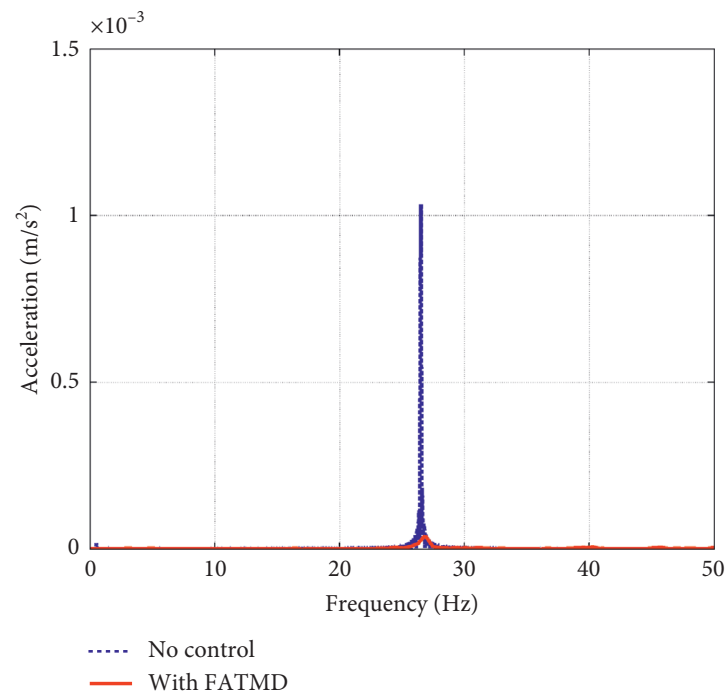

(f)

Figure 10: Continued. 

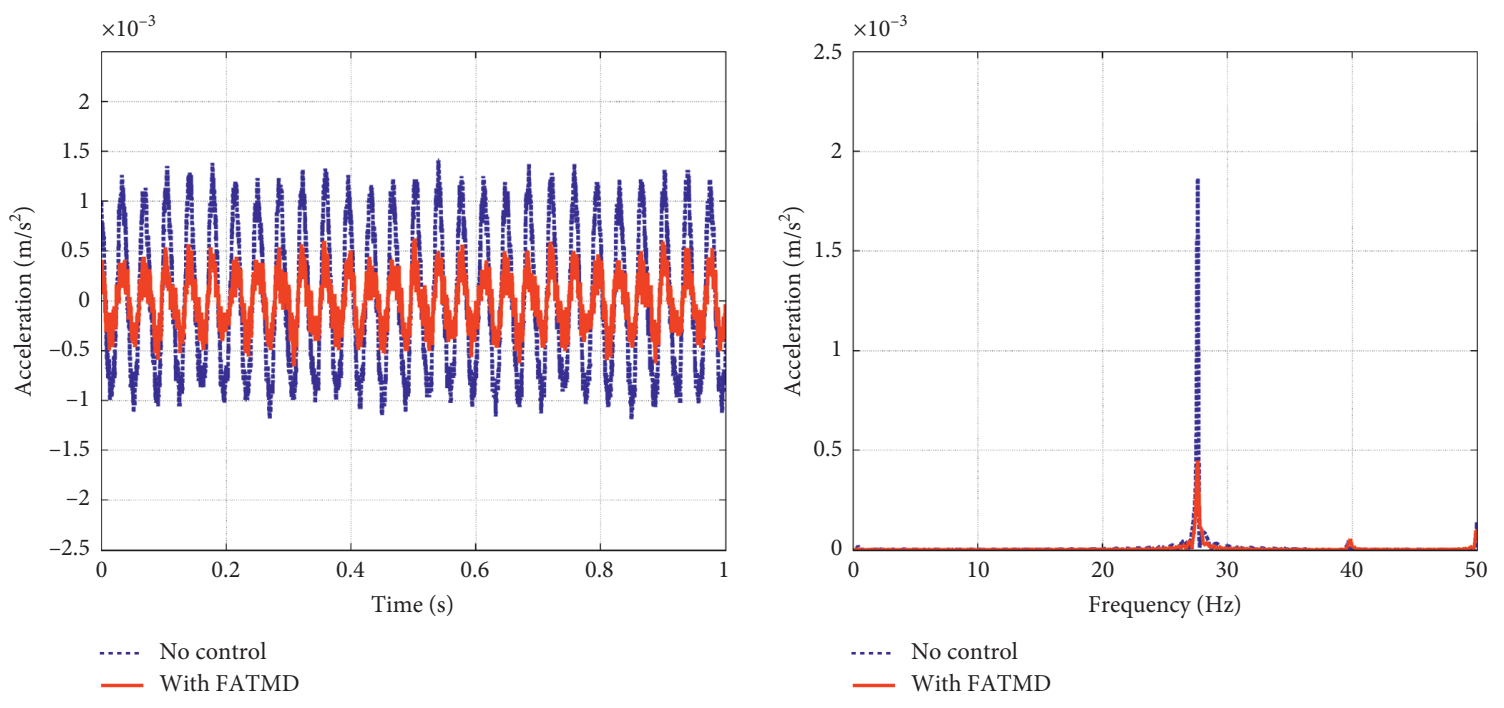

(g)

(h)
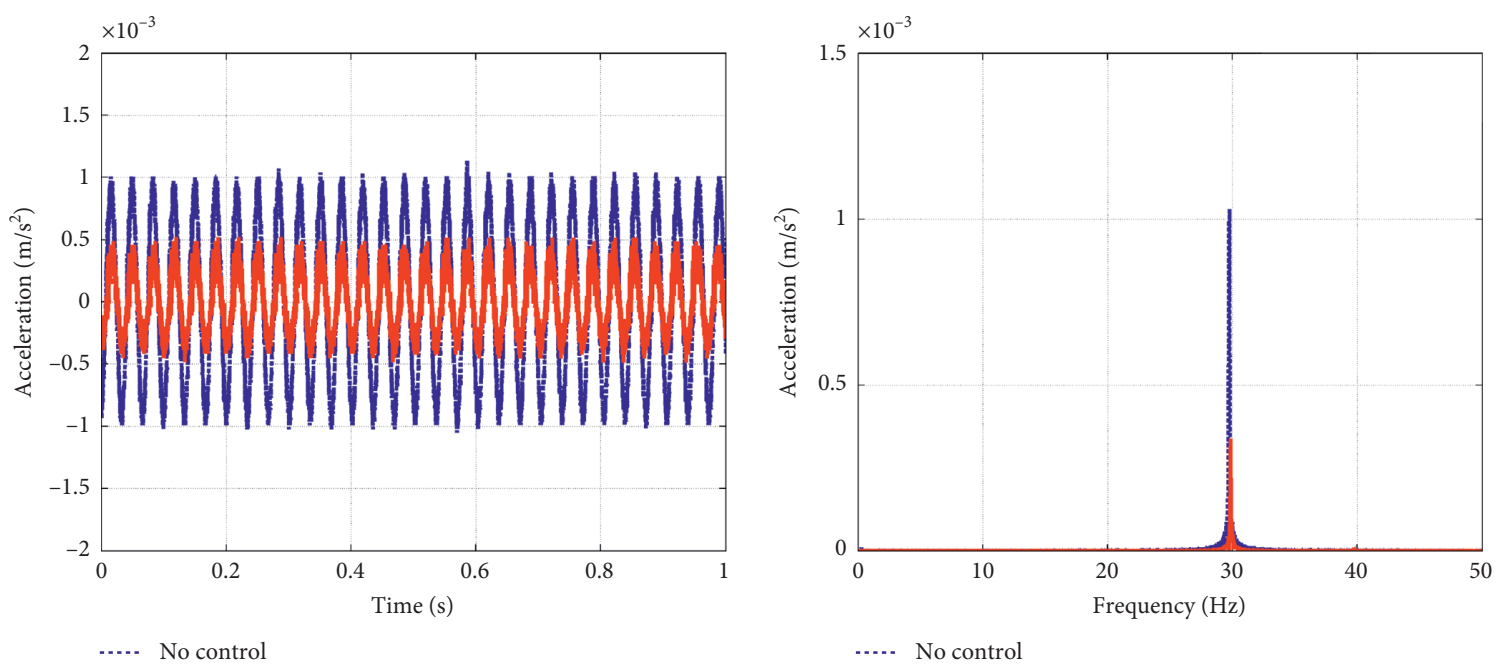

.... No control

— With FATMD

(i)

(j)
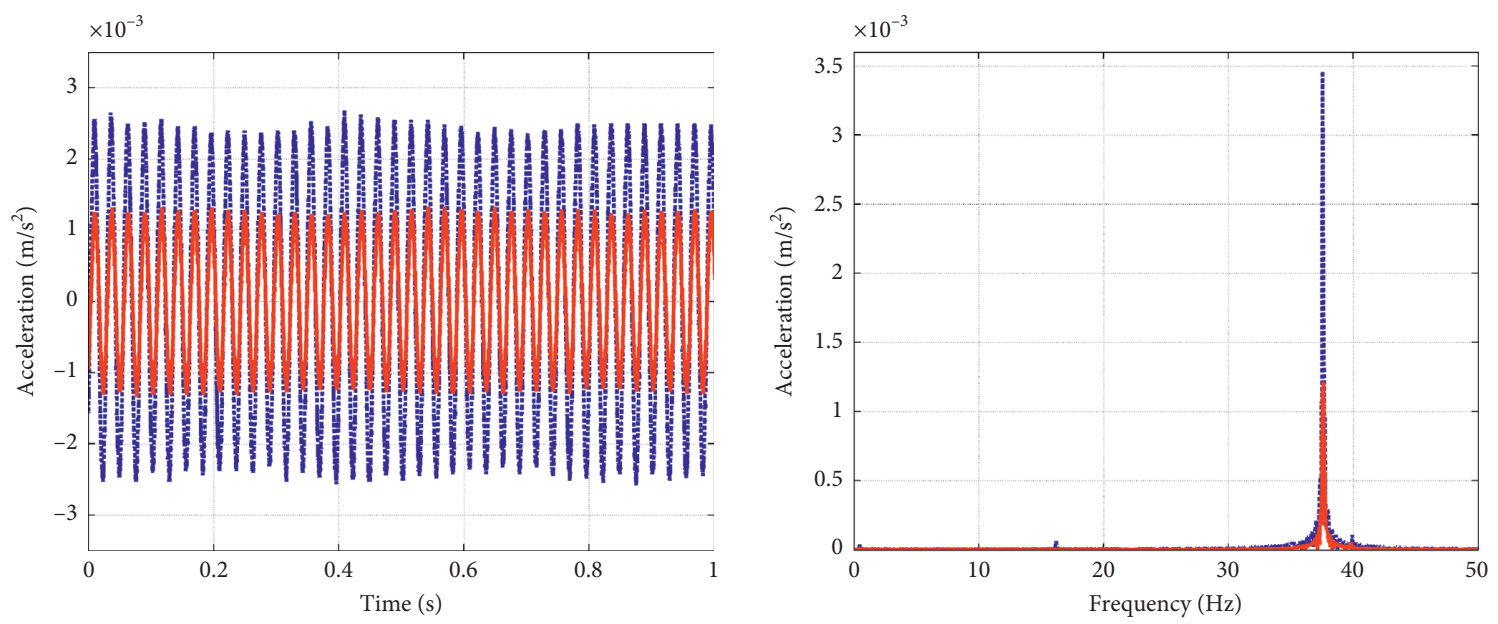

No control

No control

With FATMD

(k)

(1)

Figure 10: Continued. 


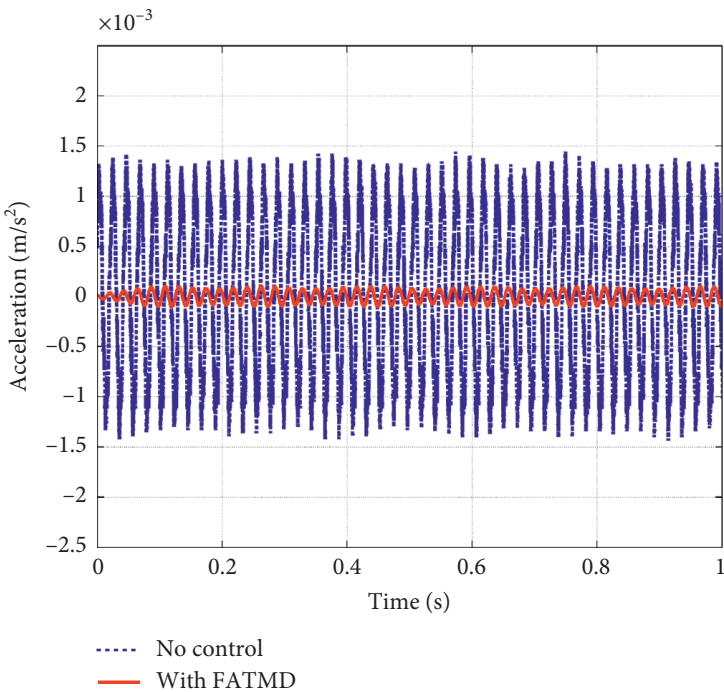

$(\mathrm{m})$

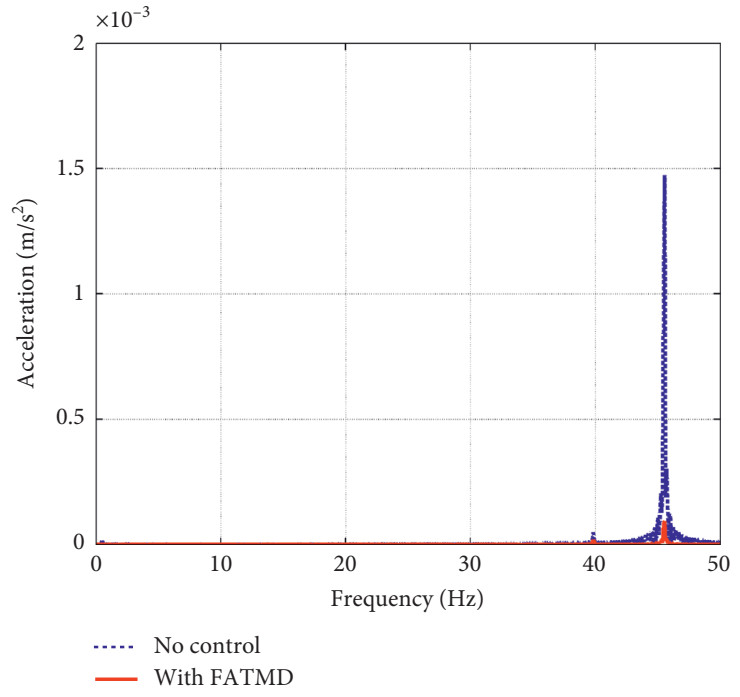

(n)

Figure 10: Acceleration of the structure with and without an FATMD for different excitation frequencies. (a) Acceleration of the structure vs. time $(f=20.1 \mathrm{~Hz}, L=1.0 \mathrm{~m})$, (b) acceleration of the structure vs. frequency $(f=20.1 \mathrm{~Hz}, L=1.0 \mathrm{~m})$, (c) acceleration of the structure vs. time $(f=23.0 \mathrm{~Hz}, L=0.9 \mathrm{~m}),(\mathrm{d})$ acceleration of the structure vs. frequency $(f=23.0 \mathrm{~Hz}, L=0.9 \mathrm{~m})$, (e) acceleration of the structure vs. time $(f=26.5 \mathrm{~Hz}, L=0.8 \mathrm{~m})$, (f) acceleration of the structure vs. frequency $(f=26.5 \mathrm{~Hz}, L=0.8 \mathrm{~m}),(\mathrm{g})$ acceleration of the structure vs. time $(f=28.5 \mathrm{~Hz}, L=0.76 \mathrm{~m}),(\mathrm{h})$ acceleration of the structure vs. frequency $(f=28.5 \mathrm{~Hz}, L=0.76 \mathrm{~m})$, (i) acceleration of the structure vs. time $(f=30.0 \mathrm{~Hz}, L=0.72 \mathrm{~m}),(\mathrm{j})$ acceleration of the structure vs. frequency $(f=30.0 \mathrm{~Hz}, L=0.72 \mathrm{~m}),(\mathrm{k})$ acceleration of the structure vs. time $(f=38.0 \mathrm{~Hz}, L=0.6 \mathrm{~m}),(\mathrm{l})$ acceleration of the structure vs. frequency $(f=38.0 \mathrm{~Hz}, L=0.6 \mathrm{~m}),(\mathrm{m})$ acceleration of the structure vs. time $(f=45.5 \mathrm{~Hz}, L=0.43 \mathrm{~m})$, and $(\mathrm{n})$ acceleration of the structure vs. frequency $(f=45.5 \mathrm{~Hz}, L=0.43 \mathrm{~m})$.

TABLE 2: Vibration reduction ratios of the FATMD.

\begin{tabular}{|c|c|c|c|}
\hline \multirow{2}{*}{ Excitation frequency $(\mathrm{Hz})$} & \multicolumn{2}{|c|}{ Acceleration $\left(\mathrm{mm} / \mathrm{s}^{2}\right)$} & \multirow{2}{*}{ Vibration reduction ratio (\%) } \\
\hline & Uncontrolled & With FATMD & \\
\hline 20.1 & 0.497 & 0.179 & 64.0 \\
\hline 23.0 & 0.685 & 0.256 & 62.6 \\
\hline 26.5 & 1.033 & 0.040 & 96.1 \\
\hline 28.5 & 1.864 & 0.447 & 76.0 \\
\hline 30.0 & 1.030 & 0.338 & 67.2 \\
\hline 31.5 & 1.108 & 0.386 & 65.2 \\
\hline 38.0 & 3.463 & 1.217 & 64.9 \\
\hline 42.7 & 1.633 & 0.407 & 75.1 \\
\hline 45.5 & 1.473 & 0.094 & 93.6 \\
\hline
\end{tabular}

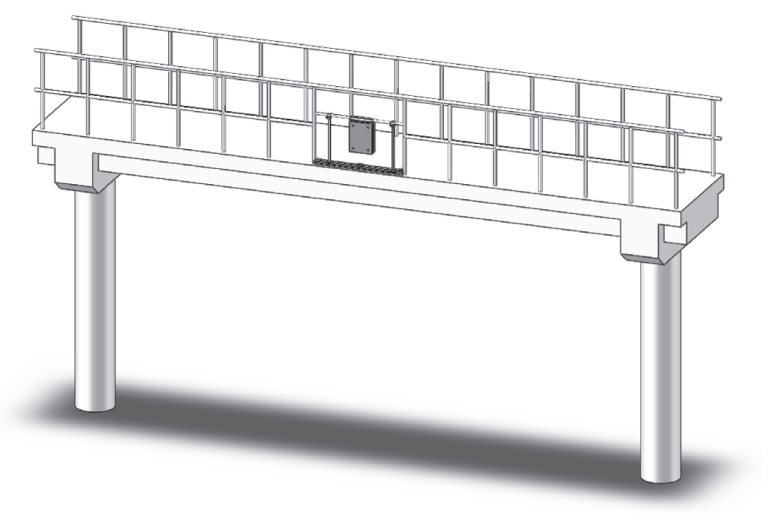

FIGURE 11: Schematic of a pedestrian bridge installed with an FATMD. 


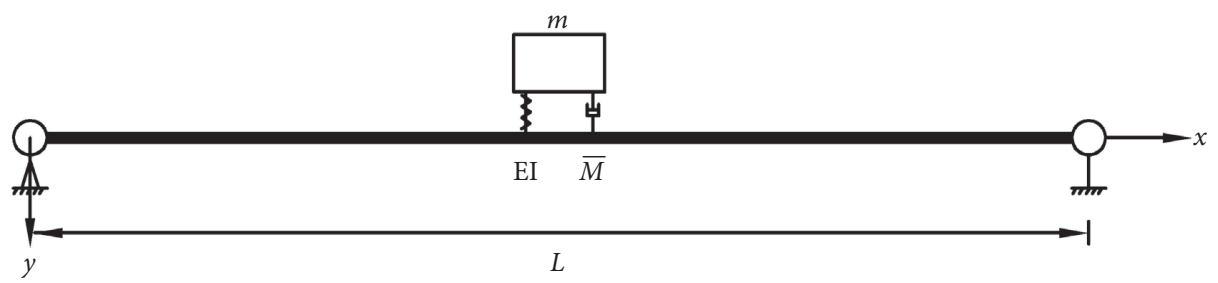

FIGURE 12: The simplified model of a pedestrian bridge with an FATMD.

damping, and stiffness of the FATMD, respectively. $y$ is the displacement of the bridge in the vertical direction. $y_{0}$ is the vertical displacement of the midspan of the bridge. $y_{1}$ is the displacement of the FATMD in the vertical direction. $F$ is the external excitation. $f$ is the control force exerted on the structure by the FATMD.

$$
f=c\left(\dot{y}_{1}-\dot{y}_{0}\right)+k\left(y_{1}-y_{0}\right) .
$$

According to the mode analysis method, the vertical responses of the bridge can be expressed as follows:

$$
y(x, t)=\sum_{n} Y_{n}(t) \phi_{n}(x)
$$

where $Y_{n}(t)$ is the generalized coordinate; $\phi_{n}(x)$ is the mode function.

$$
\phi_{n}(x)=\sin \frac{n \pi x}{L} .
$$

Thus, the kinematic equations of the bridge with the FATMD can be simplified as follows:

$$
\begin{aligned}
& \ddot{Y}_{n}+2 \xi_{n} \omega_{n} \dot{Y}_{n}+\omega_{n}^{2} Y_{n}=\frac{1}{M_{n}}\left(F_{1}+f_{1}\right) \\
& m \ddot{y}_{1}+c\left[\dot{y}_{1}-\dot{Y}_{n} \phi_{n}(x)\right]+k\left[y_{1}-Y_{n} \phi_{n}(x)\right]=0,
\end{aligned}
$$

where

$$
\begin{aligned}
M_{n}= & \int_{0}^{L} \phi_{n}^{2}(x) \bar{m} \mathrm{~d} x, \\
\omega_{n}= & n^{2} \pi^{2} \sqrt{\frac{\mathrm{EI}}{\bar{m} L^{4}}}, \\
\xi_{n}= & \frac{C_{n}}{2 M_{n} \omega_{n}}, \\
F_{1}= & \int_{0}^{L} \phi_{n}(x) F \mathrm{~d} x, \\
f_{1}= & \int_{0}^{L} \phi_{n}(x) f \mathrm{~d} x=\phi_{n}(x)\left\{c\left[\dot{y}_{1}-\dot{Y}_{n} \phi_{n}(x)\right]\right. \\
& \left.+k\left[y_{1}-Y_{n} \phi_{n}(x)\right]\right\} .
\end{aligned}
$$

According to research by Poovarodom et al. [47], the effect of the crowd dynamic load on the pedestrian bridge can be converted into a concentration force at the midspan of the bridge as follows:

$$
p(t)=0.4 W \sqrt{n_{p}} \sin \left(2 \pi f_{p} t\right)
$$

where $W$ is the average weight of pedestrians on the bridge and taken as $700 \mathrm{~N}$ in this paper; $n_{p}$ is the number of people walking on the bridge at the same time, and the maximum value can be about 265 based on the area of the bridge deck; and $f_{p}$ is the frequency of pedestrian loads.

The vertical responses of the bridge with and without the FATMD are computed under different frequencies of the pedestrian load. The frequency of the FATMD is set to match the excitation frequency. Figure 13 shows the acceleration time history in the midspan of the bridge under the frequency of the pedestrian load is $2.2 \mathrm{~Hz}$. The first $10 \mathrm{~s}$ is the forced vibration of the bridge under the pedestrian load, and the last $5 \mathrm{~s}$ is the free vibration of the bridge. It can be seen that the FATMD can effectively reduce the forced and the free vibration of the bridge. Figure 14 shows the acceleration envelope diagram of the bridge. A comparison of the two curves reveals the obvious vibration mitigation effect of the FATMD on the peak acceleration of the whole bridge. Table 3 lists the dynamic responses of the bridge with and without the FATMD under different frequencies of the pedestrian load. The results show that the FATMD can effectively suppress the maximum responses of the bridge under various frequencies of the pedestrian load, especially at the excitation frequency of $2.2 \mathrm{~Hz}$, in which the vibration reduction rate is over $75 \%$.

According to the code for design of antimicrovibration of a multistory factory floor (GB 50190-93) [48], the disturbing force of the escalators can be computed as follows:

$$
p_{0}(t)=m_{0} e_{0} \omega_{0}^{2} \sin \omega_{0} t
$$

where $m_{0}$ is the total mass of the escalators; $e_{0}$ is the eccentricity; and $\omega_{0}$ is the working circular frequency of the escalators.

In this section, the frequency of external excitation generated by the escalator is $21 \mathrm{~Hz}$ and the amplitude of the excitation is $3216.3 \mathrm{~N}$. The frequency of the FATMD is set to match the excitation frequency. Figure 15 shows the time history of the vertical acceleration in the midspan of the bridge under the action of escalators. Figure 16 shows the acceleration envelope diagram of the bridge. The results show that the FATMD can effectively reduce the vertical vibration of the bridge. The vibration reduction rate of the peak acceleration is $70.4 \%$. 


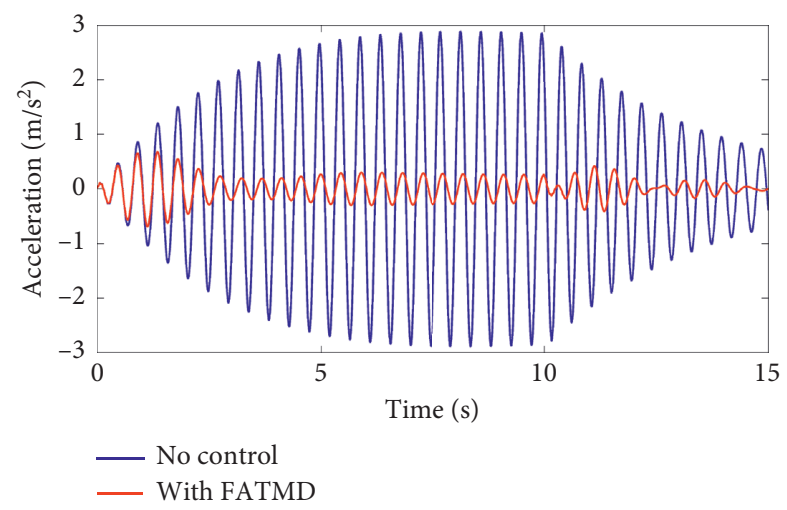

FIgURE 13: The acceleration time history in the midspan of the bridge $\left(f_{p}=2.2 \mathrm{~Hz}\right)$.

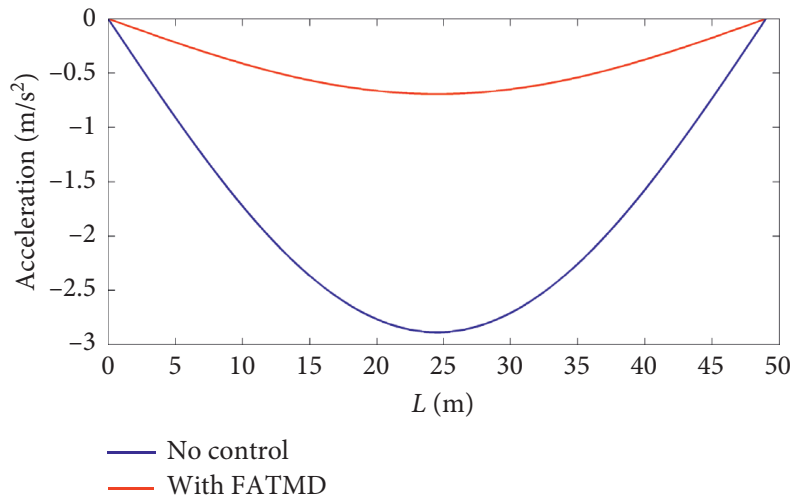

Figure 14: The acceleration envelope diagram of the bridge $\left(f_{p}=2.2 \mathrm{~Hz}\right)$.

TABLE 3: Dynamic responses in the midspan of the bridge with and without the FATMD.

\begin{tabular}{|c|c|c|c|c|c|c|}
\hline \multirow{2}{*}{$f_{p}(\mathrm{~Hz})$} & \multicolumn{2}{|c|}{ Peak displacement (mm) } & \multirow{2}{*}{ Vibration reduction ratio (\%) } & \multicolumn{2}{|c|}{ Peak acceleration $\left(\mathrm{m} / \mathrm{s}^{2}\right)$} & \multirow{2}{*}{ Vibration reduction ratio (\%) } \\
\hline & Uncontrolled & With FATMD & & Uncontrolled & With FATMD & \\
\hline 1.8 & 0.35 & 0.24 & 31.43 & 0.54 & 0.36 & 32.58 \\
\hline 2.0 & 0.57 & 0.30 & 47.37 & 0.97 & 0.50 & 48.45 \\
\hline 2.2 & 1.50 & 0.36 & 76.00 & 2.89 & 0.69 & 76.12 \\
\hline 2.5 & 0.53 & 0.24 & 54.72 & 1.20 & 0.53 & 55.83 \\
\hline
\end{tabular}

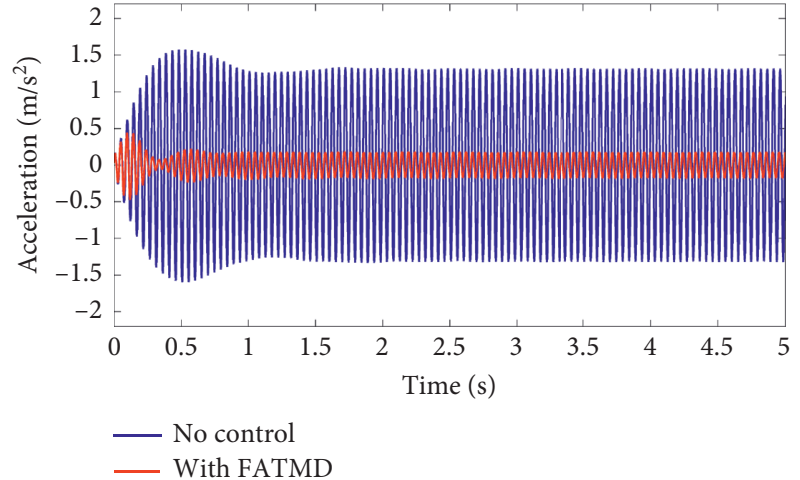

FIGURE 15: The acceleration time history in the midspan of the bridge.
Furthermore, the vertical responses of the bridge with and without the FATMD are computed under three different seismic records (Table 4), including the Imperial Valley earthquake, the Kobe earthquake, and the Borrego earthquake. The frequency of the FATMD is set to match the natural frequency of the bridge. The peak ground accelerations (PGA) of each seismic record are, respectively, adjusted to be $0.2 \mathrm{~g}$. Figure 17 shows the time history of the vertical acceleration in the midspan of the bridge under the three earthquakes. Table 5 lists the dynamic responses of the bridge with and without the FATMD under different earthquakes. It is concluded that the FATMD can effectively suppress the vertical accelerations and displacements in the midspan of the bridge under the three earthquakes. 


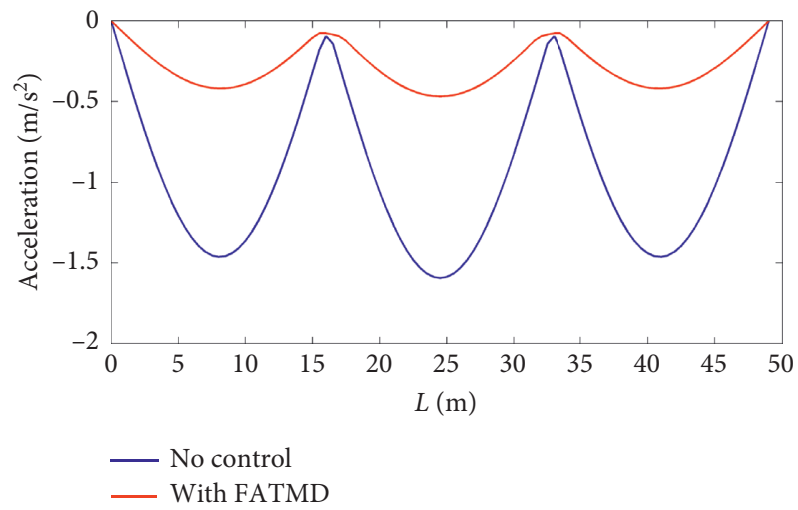

FigURE 16: The acceleration envelope diagram of the bridge.

TABle 4: Seismic records.

\begin{tabular}{lcccc}
\hline Earthquake & Event date & Recording station & Acceleration component & Peak ground acceleration $\left(\mathrm{m} / \mathrm{s}^{2}\right)$ \\
\hline Imperial Valley & $5 / 19 / 1940$ & El Centro & East-west & 0.659 \\
Kobe & $1 / 16 / 1995$ & Taka tori & North-south & 8.178 \\
Borrego & $10 / 21 / 1942$ & El Centro & East-west & 1.961 \\
\hline
\end{tabular}

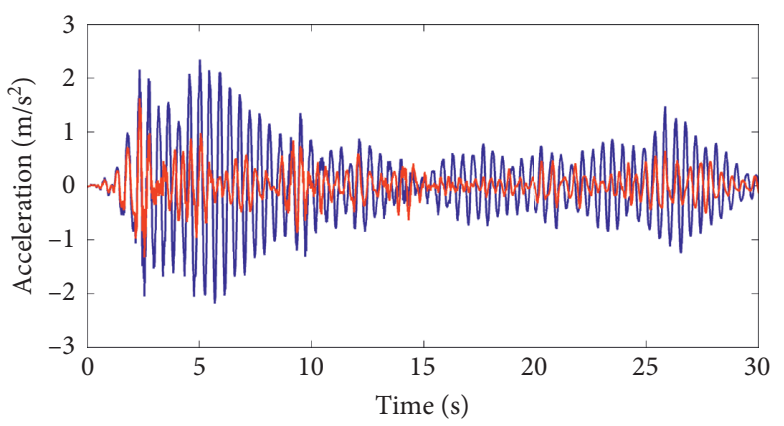

— No control — With FATMD

(a)

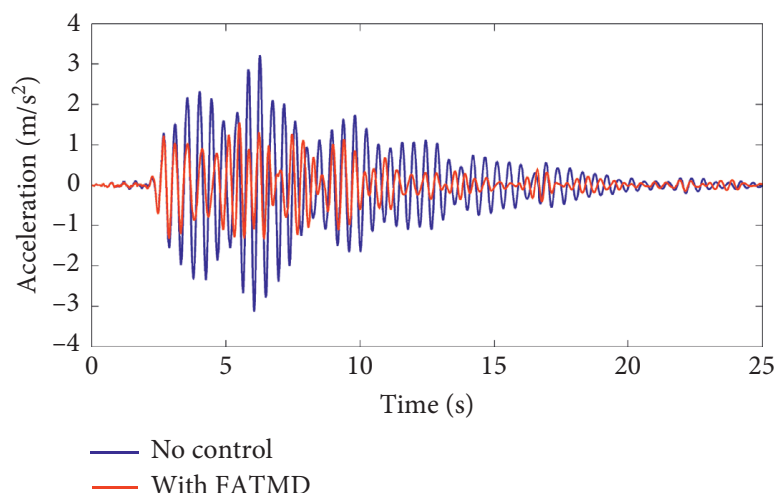

(b)

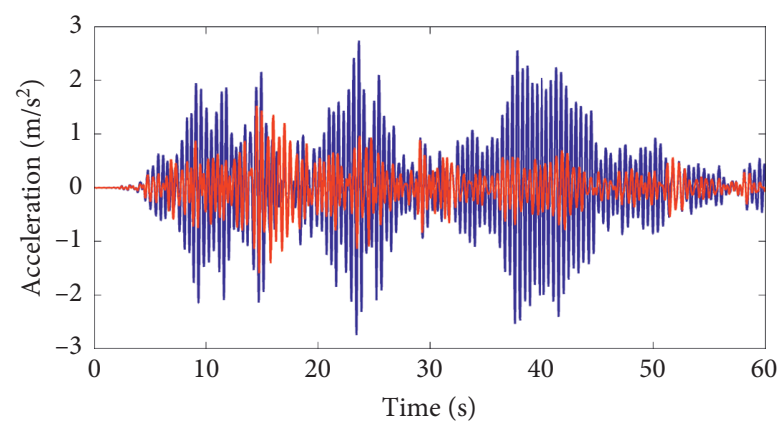

- No control

With FATMD

(c)

FIGURE 17: The acceleration time history in the midspan of the bridge. (a) Imperial Valley earthquake, (b) Kobe earthquake, and (c) Borrego earthquake. 
TABLE 5: Dynamic responses in the midspan of the bridge with and without the FATMD.

\begin{tabular}{lccc}
\hline Earthquake & Imperial Valley & Kobe & Borrego \\
\hline Peak displacement $(\mathrm{mm})$ & & & \\
Uncontrolled & 1.29 & 1.65 & 1.80 \\
With FATMD & 0.69 & 0.85 & 0.98 \\
Vibration reduction ratio (\%) & 46.51 & 48.48 & 45.56 \\
\hline Peak acceleration $\left(\mathrm{m} / \mathrm{s}^{2}\right)$ & & & \\
$\quad$ Uncontrolled & 2.34 & 3.21 & 2.74 \\
With FATMD & 1.62 & 1.55 & 1.59 \\
Vibration reduction ratio (\%) & 30.77 & 51.71 & 41.97 \\
\hline
\end{tabular}

\section{Conclusions}

In this paper, an FATMD composed of a simple supported beam with a mass is proposed to suppress high-frequency vibrations that can be generated by heavy machinery. Forced vibration experiments are conducted to verify the vibration suppression capabilities of the FATMD. Numerical and experimental analysis verified that the natural frequency of the FATMD can be adjusted and that the FATMD frequency decreases with the increased beam span. The FATMD can effectively reduce the structural vibrations at different tested high frequencies. The vibration suppression effect of the FATMD is stable between $\lambda=0.9-1.1$, with $\lambda=1.0$ being a relatively optimal value according to the curves. The vibration control effect of the FATMD increases with increased mass ratio and decreased damping ratio. Furthermore, the FATMD is an easily assembled structure that can be quickly adjusted for various natural frequencies, thus enabling the FATMD to be simpler to use than the normal TMD. The numerical results of the pedestrian bridge with an FATMD indicate that the FATMD has a significant effect on reducing the vibration of the pedestrian bridge under the excitations of pedestrians, escalators, and earthquakes.

However, the beam needs to remain in its elastic range for the FATMD to be effective, which limits the allowable range of stiffness that the FATMD can be tuned. Therefore, the FATMD may be detuned under high-intensity excitations, and its effectiveness may be significantly degraded. In the future work, the proposed FATMD will be optimally designed to improve its vibration control performance. The multiple FATMDs will be numerical and experimentally studied for the vibration control of structures with the consideration of multiple hazards, including the machine-, pedestrian-, earthquake-, and wind-induced vibrations.

\section{Data Availability}

The data used to support the findings of this study are available from the corresponding author upon request.

\section{Conflicts of Interest}

The authors declare that they have no conflicts of interest regarding the publication of this paper.

\section{Acknowledgments}

This work was partially supported by the General Project of the Natural Science Foundation of China (Grant No. 51578114).

\section{References}

[1] T.-C. Pan, A. Mita, and J. Li, "Vehicle-induced floor vibrations in a multistory factory building," Journal of Performance of Constructed Facilities, vol. 15, no. 2, pp. 54-61, 2001.

[2] J. M. W. Brownjohn, T. C. Pan, C. Middleton, S. C. Tan, and G. Yang, "Floor vibration serviceability in a multistory factory building," Journal of Performance of Constructed Facilities, vol. 30, no. 1, Article ID 04014203, 2016.

[3] N. W. M. Bishop, M. Willford, and R. Pumphrey, "Human induced loading of flexible staircases," Engineering Structures, vol. 23, no. 1, pp. 37-45, 2001.

[4] C. J. Middleton and J. M. W. Brownjohn, "Response of high frequency floors: a literature review," Engineering Structures, vol. 32, no. 2, pp. 337-352, 2010.

[5] G. E. Thermou, S. J. Pantazopoulou, and A. S. Elnashai, "Design methodology for seismic upgrading of substandard reinforced concrete structures," Journal of Earthquake Engineering, vol. 11, no. 4, pp. 582-606, 2007.

[6] C. Jaafari and J. Mohammadi, "Floor vibration control as a serviceability requirement in design standards and practices: review," Practice Periodical on Structural Design and Construction, vol. 23, no. 2, Article ID 04018003, 2018.

[7] A. Ebrahimpour and R. L. Sack, "A review of vibration serviceability criteria for floor structures," Computers \& Structures, vol. 83, no. 28-30, pp. 2488-2494, 2005.

[8] Z. Wang, F. Liu, Z. Wu, and C. Zhang, "Vibration control of floor for a flour mill building," Building Structure, vol. 45, no. 19, pp. 32-36, 2015.

[9] J. T. P. Yao, "Concept of structural control," Journal of the Structural Division, vol. 98, no. ST7, pp. 1567-1574, 1972.

[10] C.-L. Lee, Y.-P. Wang, and R. K. L. Su, "Assessment of vibrations induced in factories by automated guided vehicles," Proceedings of the Institution of Civil Engineers-Structures and Buildings, vol. 166, no. 4, pp. 182-196, 2013.

[11] T. Zordan, T. Liu, B. Briseghella, and Q. Zhang, "Improved equivalent viscous damping model for base-isolated structures with lead rubber bearings," Engineering Structures, vol. 75, pp. 340-352, 2014.

[12] M. Setareh, J. K. Ritchey, and T. M. Murray, "A study of the application of the pendulum tuned mass dampers in building floor vibration controls," in Proceedings of the Second International Conference on High Performance Structures and Materials, pp. 287-296, Ancona, Italy, 2004.

[13] Z. Sun, Z. L. Zou, X. Y. Ying, and X. Q. Li, "Tuned mass dampers for wind-induced vibration control of chongqi bridge," Journal of Bridge Engineering, vol. 25, no. 1, Article ID 05019013, 2020.

[14] E. Caetano, Á. Cunha, F. Magalhães, and C. Moutinho, "Studies for controlling human-induced vibration of the Pedro e Inês footbridge, Portugal. Part 1: assessment of dynamic behaviour," Engineering Structures, vol. 32, no. 4, pp. 1069-1081, 2010.

[15] E. Caetano, Á. Cunha, C. Moutinho, and F. Magalhães, "Studies for controlling human-induced vibration of the Pedro e Inês footbridge, Portugal. Part 2: implementation of tuned mass dampers," Engineering Structures, vol. 32, no. 4, pp. 1082-1091, 2010. 
[16] N. Carpineto, W. Lacarbonara, and F. Vestroni, "Mitigation of pedestrian-induced vibrations in suspension footbridges via multiple tuned mass dampers," Journal of Vibration and Control, vol. 16, no. 5, pp. 749-776, 2010.

[17] L. S. Vellar, S. P. Ontiveros-Perez, L. F. F. Miguel, and L. F. F. Miguel, "Robust optimum design of multiple tuned mass dampers for vibration control in buildings subjected to seismic excitation," Shock and Vibration, vol. 2019, Article ID 9273714, 9 pages, 2019.

[18] S. Elias, R. Rupakhety, and S. Olafsson, "Analysis of a benchmark building installed with tuned mass dampers under wind and earthquake loads," Shock and Vibration, vol. 2019, Article ID 7091819, 13 pages, 2019.

[19] R. R. Gerges and B. J. Vickery, "Parametric experimental study of wire rope spring tuned mass dampers," Journal of Wind Engineering and Industrial Aerodynamics, vol. 91, no. 12-15, pp. 1363-1385, 2003.

[20] E.-M. He, Y.-Q. Hu, and Y. Zhang, "Optimization design of tuned mass damper for vibration suppression of a barge-type offshore floating wind turbine," Proceedings of the Institution of Mechanical Engineers, Part M: Journal of Engineering for the Maritime Environment, vol. 231, no. 1, pp. 302-315, 2017.

[21] Q. Wu, W. Zhao, W. G. Zhu, R. C. Zheng, and X. L. Zhao, "A tuned mass damper with nonlinear magnetic force for vibration suppression with wide frequency range of offshore platform under earthquake loads," Shock and Vibration, vol. 2018, Article ID 1505061, 18 pages, 2018.

[22] S. V. Bakre and R. S. Jangid, "Optimum parameters of tuned mass damper for damped main system," Structural Control and Health Monitoring, vol. 14, no. 3, pp. 448-470, 2007.

[23] Y.-J. Kang and L.-Y. Peng, "Optimisation design and damping effect analysis of large mass ratio tuned mass dampers," Shock and Vibration, vol. 2019, Article ID 8376781, 16 pages, 2019.

[24] Z. Lu, D. Wang, and Y. Zhou, "Experimental parametric study on wind-induced vibration control of particle tuned mass damper on a benchmark high-rise building," The Structural Design of Tall and Special Buildings, vol. 26, no. 8, p. e1359, 2017.

[25] Z. Lu, B. Huang, Q. Zhang, and X. Lu, "Experimental and analytical study on vibration control effects of eddy-current tuned mass dampers under seismic excitations," Journal of Sound and Vibration, vol. 421, pp. 153-165, 2018.

[26] P. Zhang, G. Song, H.-N. Li, and Y.-X. Lin, "Seismic control of power transmission tower using pounding TMD," Journal of Engineering Mechanics, vol. 139, no. 10, pp. 1395-1406, 2013.

[27] Q. C. Xue, J. C. Zhang, J. He, and C. W. Zhang, "Control performance and robustness of pounding tuned mass damper for vibration reduction in SDOF structure," Shock and Vibration, vol. 2016, Article ID 8021690, 15 pages, 2016.

[28] H. He, W. Wang, and H. Xu, "Multidimensional seismic control by tuned mass damper with Poles and torsional pendulums," Shock and Vibration, vol. 2017, Article ID 5834760, 14 pages, 2017.

[29] M. D. S. D. Santos, D. V. F. Lima, J. E. C. Carmona, S. M. Avila, and G. N. D. D. Carvalho, "Vibration control of a gym floor using tuned mass dampers: a numerical analysis," Modern Mechanical Engineering, vol. 3, no. 3, pp. 9-16, 2013.

[30] D.-C. Nguyen, "Determination of optimal parameters of the tuned mass damper to reduce the torsional vibration of the shaft by using the principle of minimum kinetic energy," Proceedings of the Institution of Mechanical Engineers, Part K: Journal of Multi-Body Dynamics, vol. 233, no. 2, pp. 327-335, 2019.
[31] Y. S. Tarng, J. Y. Kao, and E. C. Lee, "Chatter suppression in turning operations with a tuned vibration absorber," Journal of Materials Processing Technology, vol. 105, no. 1-2, pp. 55-60, 2000.

[32] Y. Yang, J. Munoa, and Y. Altintas, "Optimization of multiple tuned mass dampers to suppress machine tool chatter," International Journal of Machine Tools and Manufacture, vol. 50, no. 9 , pp. $834-842$.

[33] M.-L. Chang, C.-C. Lin, J.-M. Ueng, K.-H. Hsieh, and J.-F. Wang, "Experimental study on adjustable tuned mass damper to reduce floor vibration due to machinery," Structural Control and Health Monitoring, vol. 17, no. 5, pp. 532-548, 2010.

[34] M. Abdel-Rohman, M. J. John, and M. F. Hassan, "Compensation of time delay effect in semi-active controlled suspension bridges," Journal of Vibration and Control, vol. 16, no. 10, pp. 1527-1558, 2010.

[35] G. Jiang and L. M. Hanagan, "Semi-active TMD with piezoelectric friction dampers in floor vibration control," in Proceedings of the Smart Structures and Materials 2006: Damping and Isolation, San Diego, CA, USA, 2006.

[36] K. Esteki, A. Bagchi, and R. Sedaghati, "Semi-active control of seismic response of a building using MR fluid-based tuned mass damper," Smart Structures and Systems, vol. 16, no. 5, pp. 807-833, 2015.

[37] N. Varadarajan and S. Nagarajaiah, "Wind response control of building with variable stiffness tuned mass damper using empirical mode decomposition/hilbert transform," Journal of Engineering Mechanics, vol. 130, no. 4, pp. 451-458, 2004.

[38] S. Nagarajaiah, "Adaptive passive, semiactive, smart tuned mass dampers: identification and control using empirical mode decomposition, hilbert transform, and short-term fourier transform," Structural Control and Health Monitoring, vol. 16, no. 7-8, pp. 800-841, 2010.

[39] M. W. Ryan, M. A. Franchek, and R. Bernhad, "Adaptivepassive vibration control of single frequency excitations applied to noise control," in Proceedings of the 1994 National Conference on Noise Control Engineering, pp. 461-466, Fort Lauderdale, FL, USA, 1994.

[40] M. T. Contreras, D. T. R. Pasala, and S. Nagarajaiah, "Adaptive length SMA pendulum smart tuned mass damper performance in the presence of real time primary system stiffness change," Smart Structures and Systems, vol. 13, no. 13, pp. 219-233, 2014.

[41] S. Nagarajaiah and D. T. R. Pasala, "NEESR-adapt-struct: semi-active control of ASD device-adaptive length pendulum dampers," in Proceedings of the Analysis and Computation Specialty Conference, pp. 325-334, Orlando, FL, USA, 2010.

[42] O. B. Mekki, F. Bourquin, F. Maceri, and C. N. Van Phu, "An adaptive pendulum for evolving structures," Structural Control and Health Monitoring, vol. 19, no. 1, pp. 43-54, 2012.

[43] W. Shi, L. Wang, and Z. Lu, "Study on self-adjustable tuned mass damper with variable mass," Structural Control and Health Monitoring, vol. 25, no. 3, p. e2114, 2018.

[44] I. Venanzi, F. Ubertini, and A. L. Materazzi, "Optimal design of an array of active tuned mass dampers for wind-exposed high-rise buildings," Structural Control and Health Monitoring, vol. 20, no. 6, pp. 903-917, 2013.

[45] M. S. Rahman, M. K. Hassan, S. Chang, and D. Kim, "Adaptive multiple tuned mass dampers based on modal parameters for earthquake response reduction in multi-story buildings," Advances in Structural Engineering, vol. 20, no. 9, pp. 1375-1389, 2017. 
[46] H. Sun, W. Wang, H. Ding, J. Li, and C. Zhang, "Natural frequency measurement of pipe vibration for vortex flowmeter," in Proceedings of the 2019 IEEE International Instrumentation and Measurement Technology Conference, Auckland, New zealand, 2019.

[47] N. Poovarodom, S. Kanchanosot, and P. Warnitchai, "Application of non-linear multiple tuned mass dampers to suppress man-induced vibrations of a pedestrian bridge," Earthquake Engineering \& Structural Dynamics, vol. 32, no. 7, pp. 1117-1131, 2003.

[48] GB50190-93, Code for Design of Anti-microvibration of Multistory Factory Floor, China Planning Press, Beijing, China, 1994. 